\title{
Reduced bone density in patients with inflammatory bowel disease
}

\author{
I Bjarnason, A Macpherson, C Mackintosh, M Buxton-Thomas, I Forgacs, C Moniz
}

\begin{abstract}
Background-Reduced bone mineral density in patients with inflammatory bowel disease is thought to be due to disturbances in calcium homeostasis or the effects of corticosteroid treatment. Aims-To assess the prevalence and mechanism of reduced bone mineral density in 79 patients with inflammatory bowel disease (44 with Crohn's disease, 35 with ulcerative colitis) who did not have significant risk factors for low bone densities. Methods-Dual $x$ ray absorptiometry was used to measure bone mineral density and serum and urinary markers of osteoblast (alkaline phosphatase, procollagen 1 carboxy terminal peptide and osteocalcin) and osteoclast (pyridinoline, deoxypyridinoline, and type 1 collagen carboxy terminal peptide) activities to assess bone turnover.

Results-There was a high prevalence of low bone mineral density (prevalence of $T$ scores $<-1.0$ from $51 \%-77 \%$; T scores $<-2 \cdot 5$ (osteoporosis) from $17 \%-28 \%$ ) with hips being more often affected than vertebrae (p<0.001). Reduced bone mineral density did not relate to concurrent or past corticosteroid intake, or type, site, or severity of disease. Whereas calcium homeostasis was normal, bone markers showed increased bone resorption without a compensatory increase in bone formation.

Conclusions-The greater prevalence of reduced hip bone mineral density, as opposed to vertebral, mineral density and the pattern of a selective increase in bone resorption contrasts with that found in other known causes of metabolic bone disease.

(Gut 1997; 40: 228-233)
\end{abstract}

Keywords: hip bone density, vertebral bone density, inflammatory bowel disease.

Departments of Clinical Biochemistry, Medicine, Gastroenterology and Nuclear Medicine, King's College Hospital, London I Bjarnason

A Macpherson

C Mackintosh

M Buxton-Thomas

I Forgacs

C Moniz

Correspondence to Dr I Bjarnason, Department of Clinical Biochemistry, King's College Hospital, Bessemer Road, London SE5 9PJ.

Accepted for publication 22 October 1996 phy, CT, and single or dual photon or $x$ ray absorptiometry) which differ in their sensitivity and specificity. Current consensus is that osteoporosis is found in $30 \%-45 \%$ of patients with Crohn's disease and somewhat less often in patients with ulcerative colitis. ${ }^{4}$ The higher prevalence of bone disease in patients with Crohn's disease is thought to relate to ileal and small intestinal involvement of disease or surgical resections causing vitamin $\mathrm{D}$ or calcium malabsorption, oestrogen deficiency, malnutrition, or treatment with cholestyramine. ${ }^{24-8}$ In ulcerative colitis and Crohn's colitis osteoporosis is usually ascribed to corticosteroid treatment. Collectively it is suggested that the pathogenesis of bone disease in patients with inflammatory bowel disease is multifactorial. At the same time the patient groups studied have been heterogeneous in relation to the various confounding variables affecting bone metabolism.

Recently it has become possible to measure markers in urine and serum which reflect osteoblast and osteoclast function and hence bone turnover. Osteoblast markers, reflecting the rate of bone formation, include serum bone specific alkaline phosphatase, osteocalcin, and procollagen I carboxy terminal peptide (P1CP). The osteoclast markers, reflecting the rate of bone resorption, are degradation products of type 1 collagen fibril cross links released in response to osteoclast activity, and include urinary pyridinoline, deoxypyridinoline, and serum type 1 collagen carboxy terminal teleopeptide (1CTP).

We assessed the prevalence and possible mechanism of metabolic bone disease by measuring bone density with dual $x$ ray absorptiometry (DXA) and by measurement of calcium homeostasis and markers of osteoblast and osteoclast activities in a group of patients with ulcerative colitis and Crohn's disease who were not thought to be at significant risk of reduced bone mineral density and who had a low lifetime intake of corticosteroids.

\section{Subjects and methods}

White patients with classic inflammatory bowel disease (ulcerative colitis or Crohn's disease, diagnosed by a combination of radiology, endoscopy, and biopsy) aged $20-80$ years and attending a gastrointestinal outpatient clinic were invited to participate in this study. Patients thought to be at risk for metabolic bone disease were specifically excluded from this study - namely, those having undergone intestinal resection, patients requiring treatment for cardiopulmonary, hepatic, or renal disease, and those who had established chronic inflammatory joint disease (extraintestinal manifestations of inflammatory bowel disease, ankylosing spondylitis, rheumatoid arthritis, etc) or who were already receiving treatment for osteoporosis, patients who clearly had malnutrition (body mass index <20), and patients receiving more than $10 \mathrm{mg}$ prednisolone/day in the preceding six weeks or a 
lifetime intake $>25 \mathrm{~g}$, and patients with indeterminate colitis. Subsequently, all the patients had inactive disease as defined by a clinical Crohn's disease activity index $<150^{9}$ or the criteria of Truelove and Witts. ${ }^{10}$ Postmenopausal women and those with amenorrhoea as a consequence of disease activity (an effect on hypothalamic releasing hormones leading to relative hypo-oestrogenaemia) were also excluded because of the known effects of low oestroens on bone metabolism.

Seventy nine patients were recruited for study. Forty four had Crohn's disease (13 small intestinal or ileal, 16 ileocaecal or ileocolonic, 15 colonic) and 35 had ulcerative colitis (21 proctitis, 14 left sided or total involvement). Their mean (SD) age was 39 (14) years. There were 34 men (mean age 45 (17), range 20-77 years, height $169(12) \mathrm{cm}$, weight 62 (11) kg, and body mass index 23 (4), range $20-28$ ) and 45 women (mean age 33 (7), range 20-25 years, height $161(11) \mathrm{cm}$, weight $60(10) \mathrm{kg}$, and body mass index 23 (3), range 20-26) and the duration of disease ranged from newly diagnosed $(n=14)$ to 30 years (mean 7.9). Nineteen were taking prednisolone (11 receiving $10 \mathrm{mg} /$ day and eight $5 \mathrm{mg} /$ day) whereas 23 had never received corticosteroids. Twelve patients smoked cigarettes regularly. None of these variables differed significantly $(p>0.5)$ according to subgroups of type or location of disease.

The studies were approved by the Camberwell Health Authority ethics committee and each patient gave informed consent to these studies.

\section{Investigations}

Routine haematological (haemoglobin, packed cell volume, white cell differential, and erythrocyte sedimentation rate) and biochemical variables (electrolytes, glucose, renal and liver profiles) were measured. Additionally, calcium homeostasis was assessed by measurement of fasting serum and urine calcium and serum phosphate (measured on a Technicon DAX 48 multichannel analyser (Bayer Diagnostics, Basingstoke, UK)) by standard methods. The normal ranges for routine haematology and biochemistry variables had been established at King's College Hospital in cohorts of 100-300 normal subjects. We used the manufacturer's recommendation for the normal range of parathyroid hormone concentrations (immunoassay, Nicholls Institute, Newport, Essex, UK), which is based on a white north European population.

\section{Bone density measurement}

Bone mineral density was measured by a single operator with subjects in the supine position. The interassay coefficient of variation for spine bone density measurements using a Norland phantom was $1 \cdot 2 \%$ and for hip $1.7 \%$, by DXA (Norland XR-26 Bone Densitometer, Norland Corporation, Fort Atkinson, USA) at 2, 3, and 4 lumbar vertebrae. An average of the three sites was taken for expressing spine bone mineral density. At the proximal femur three sites (femoral neck, trochanter, and Ward's triangle) were measured; results for hips were given as the first site only. To determine the prevalence of low bone mass in this group of patients, results for bone mineral density were expressed as the number of standard deviations above or below the age and sex adjusted reference values of young healthy adults ( $T$ score). ${ }^{11}$

Reference values for men and women were supplied by Norland using measurements from a normal white north European population. This database had previously been compared with that obtained from 124 normal, local, white postmenopausal women (mean age 57 (SD) (range 51-62) years) with good agreement. Measurements showed a mean bone mineral density for spine of $0.93 \mathrm{~g} / \mathrm{cm}^{2} \mathrm{com}-$ pared with Norland's reference value of 0.96 $\mathrm{g} / \mathrm{cm}^{2}(\mathrm{p}>0.5)$ whereas bone mineral density of the femur $\left(0.79 \mathrm{~g} / \mathrm{cm}^{2}\right)$, trochanter $(0.79$ $\left.\mathrm{g} / \mathrm{cm}^{2}\right)$, and Ward's triangle $\left(0.69 \mathrm{~g} / \mathrm{cm}^{2}\right)$ were equal to the Norland normal data base. ${ }^{11}$ A T score $<-1.0$ was chosen as denoting reduced bone mineral density (osteopenia between $-1 \cdot 0$ and $-2 \cdot 5^{12}$ ) and a value $<-2.5$ as severely reduced bone mineral density (osteoporosis: $T$ scores $\left.<-2 \cdot 5^{12}\right)$.

\section{Osteoblast activity estimations}

All blood samples were obtained in the morning after an overnight fast. Serum was stored at $-70^{\circ} \mathrm{C}$ until analysis (within three months). The first urine sample after the overnight fast was discarded and a $30 \mathrm{ml}$ aliquot of the next urine passed was rapidly frozen and stored at $-70^{\circ} \mathrm{C}$ until analysed (within two months).

Serum total alkaline phosphatase was measured on an automated analyser (DAX) using a colorimetric assay with n-nitrophenolphosphate in diethanolamine buffer $(\mathrm{pH}$ $9 \cdot 7-9.8$ at $\left.37^{\circ} \mathrm{C}\right) ; 150$ normal white subjects defined the normal ranges.

Measurement of P1CP was carried out in fasting serum samples using a radioimmunoassay kit (Orion Diagnostica, Oulusalo, Finland). The method uses a purified and well characterised type 1 procollagen derived from human skin fibroblasts as a standard preparation and a ${ }^{125} \mathrm{I}$ labelled tracer. ${ }^{13}$ The assays were performed with polyclonal rabbit antibodies as specified in the manufacturer's instructions. The radioisotope was counted at appropriate channel settings in an LKB Wallac 1260 gamma counter (Kabi-Pharmacia, Milton Keynes, UK) for 200 seconds. Results were calculated by the LKB CALC programme using a spline smoothed curve fitting algorithm. The intra-assay and interassay coefficients of variation were $3 \cdot 2 \%$ and $6.5 \%$ respectively.

Serum osteocalcin (bone gla-protein) was measured using a solid phase sandwich enzyme linked immunosorbent assay. ${ }^{14}$ The method uses micotitre plates coated with a monoclonal antibody directed toward bovine osteocalcin, a human bone derived osteocalcin standard 


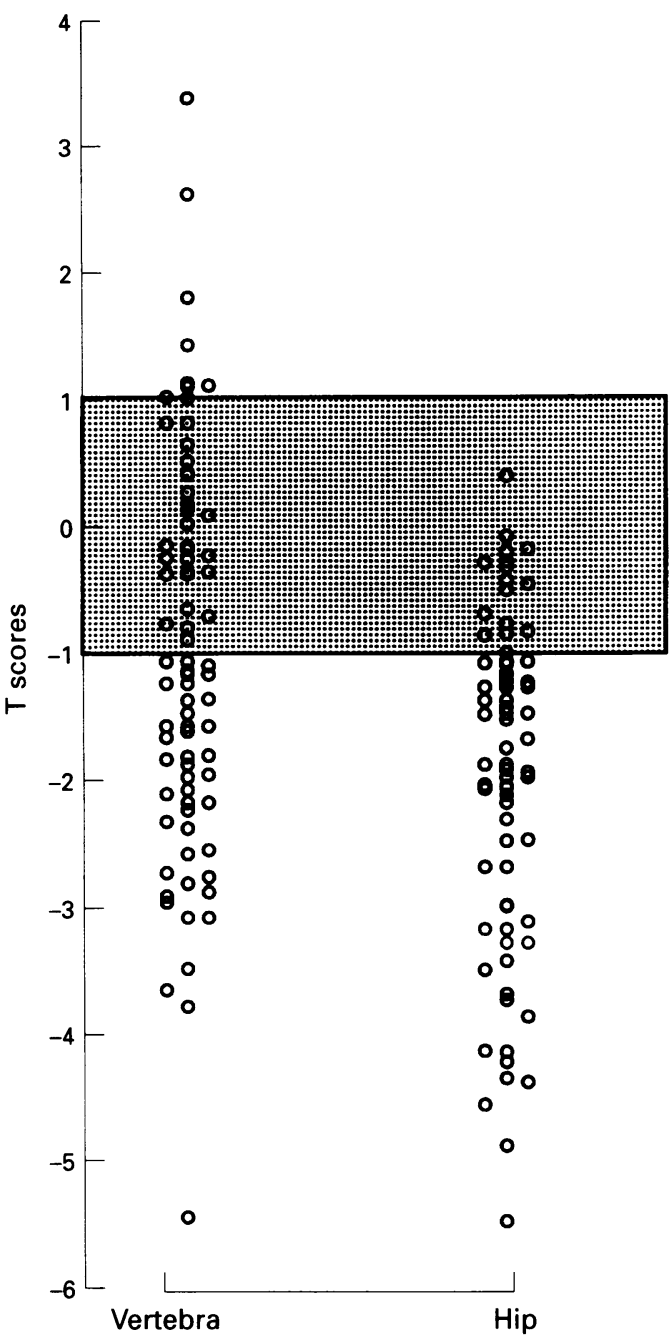

Figure 1: Vertebral and hip bone densities in patients with inflammatory bowel disease. The shaded area represents the reference range for the young adult mean (SD), values of

$-1 \cdot 0$ to $-2 \cdot 5$ being indicative of osteopenia and values $<-2 \cdot 5$ osteoporosis. ${ }^{11}$

preparation, and a polyclonal antihuman osteocalcin antibody in the sandwich assay. The intra-assay and interassay coefficients of variation in the range of values $1.5-31.0 \mu \mathrm{g} / \mathrm{l}$ were less than $8 \%$ and $15 \%$ respectively.

\section{Osteoclast activity estimations}

Pyridinoline and deoxypyridinoline were measured in urine. Urine $(1 \mathrm{ml})$ was hydrolysed in an equal volume of concentrated hydrochloric acid at $116^{\circ} \mathrm{C}$ for 16 hours followed by extraction with a CF1 column before freeze drying and reconstituting in $0.05 \mathrm{M}$ hydrochloric acid. Separation was achieved by high pressure liquid chromatography (HPLC) with

TABLE I Prevalence and severity of reduced bone mineral density in patients with inflammatory bowel disease

\begin{tabular}{lllll}
\hline & $\begin{array}{l}\text { No of } \\
\text { patients }\end{array}$ & $\begin{array}{l}\text { Scores } \\
\text { Mean }(S D)\end{array}$ & Patients $n(\%)$ & \\
\cline { 5 - 5 } & 7 scores $<-1 \cdot 0$ & $T$ scores $<-2 \cdot 5$ \\
\hline Vertebral T scores & 79 & $-0.93(1.64)^{\star \star \star}$ & $43(54 \%)$ & $14(18 \%)$ \\
Hip T scores & 79 & $-1.92(1.46)$ & $62(78 \%)$ & $23(29 \%)$ \\
\hline
\end{tabular}

$\star \star \star \mathrm{p}<0.001 v$ hip T scores.

The prevalence of reduced bone mineral bone density (osteopenia: scores $<-1$ ) was significantly greater $(p<0.008)$ in hips than vertebrae. Hip T scores showed significantly $(p<0.01)$ higher prevalence of osteoporosis than vertebra $T$ scores. a Hypersil ODS $(5 \mu \mathrm{m})$ column $(15 \mathrm{~cm} \times 4.6$ $\mathrm{mm}$, Jones Chromatography (Hengoed, Wales) and a mobile phase of $25 \mathrm{mM}$ sodium formate, $5 \mathrm{mM}$ 1-octanesulphonic acid, $1 \mathrm{mM}$ EDTA, $\mathrm{pH} 3 \cdot 25$, and methanol $(17 \cdot 5 \%$ by volume) with a flow rate of $1.5 \mathrm{ml} / \mathrm{min}$.

The native fluorescence of pyridinoline and deoxypyridinoline was measured using a RF 535 fluorescence HPLC monitor (Shimadzu, Dyson Instruments, Hetton, Tyne and Wear, UK) with excitation and emission wavelengths of 290 and $400 \mathrm{~nm}$ respectively. The peak areas were integrated with an SP 4400 integrator (Thermo Separation Products, Stone, Cheshire, UK). The concentrations of pyridinoline and deoxypyridinoline were expressed as $\mathrm{nmol} /$ mmol creatinine. The intra-assay and interassay coefficients of variation for these measurements were $<7 \%$ and $15 \%$ respectively.

Measurement of ICTP was by radioimmunoassay using a commercial kit (Orion Diagnostica), according to the manufacturer's instructions. The standard and antigen were prepared from human bone and were thoroughly characterised. ${ }^{15}$ The intra-assay coefficients of variation of serum samples containing 1.9 and $6.3 \mathrm{ng} / \mathrm{ml} 1 \mathrm{CTP}$ were 7.3 and $3.3 \%$ and interassay coefficients of variation were $7 \cdot 8 \%$ and $12 \cdot 6 \%$.

Normal serum and urine osteoblast and osteoclast marker activities were obtained from a group of apparently healthy controls, varying in number from 40 to 124 , who had a similar age and sex distribution to the disease study population. The data did not differ significantly from the manufacturer's quoted data base, which is based on a large number of apparently healthy white north European subjects. There was no significant difference in the normal ranges from the various markers with age in men (age 20-80 years) or between men and women in the age range 20 years to menopause.

\section{Statistics}

Students $t$ test was used to assess statistical differences between normal variables and those obtained in patients with inflammatory bowel disease. The differences between subgroups of inflammatory bowel disease were assessed by Wilcoxon's rank sum test. Pearson's correlation coefficient was used for correlation.

\section{Results}

Bone mineral density measurement

The mean (SD) bone densities for lumbar spine (L2-4) and hip neck from patients with inflammatory bowel disease were $0.994(0.177)$ $\mathrm{g} / \mathrm{cm}^{2}$ and $0.815(0.137) \mathrm{g} / \mathrm{cm}^{2}$ respectively. Figure 1 shows the vertebral and hip $\mathrm{T}$ scores. Table I shows that the prevalence of low bone mineral density was significantly greater $(p<0.001)$ in the hips than vertebrae. The number of patients with severely reduced bone mineral density of vertebrae (osteoporosis: $T$ scores below $-2 \cdot 5$ ) was significantly less than hips $(p<0.05)$. There was no significant sex 
TABLE II Hip $T$ scores and bone turnover markers

\begin{tabular}{|c|c|c|c|c|c|}
\hline \multirow[b]{2}{*}{$T$ scores } & \multicolumn{3}{|c|}{ Osteoclast markers } & \multicolumn{2}{|c|}{ Osteoblast markers } \\
\hline & Pyridinoline & Deoxypyridinoline & $1 C T P$ & $P 1 C P$ & Osteocalcin \\
\hline $\begin{array}{l}>-1.0 \\
-1.0 \text { to }-2.5 \\
<-2.5\end{array}$ & $\begin{array}{l}50 \cdot 7(22 \cdot 7) \\
55 \cdot 7(32 \cdot 1) \\
36 \cdot 4(8 \cdot 5)\end{array}$ & $\begin{array}{r}12.7(6.5) \\
12.4(7.9) \\
8.2(2.5)\end{array}$ & $\begin{array}{l}3 \cdot 0(1 \cdot 2) \\
4 \cdot 1(3 \cdot 5) \\
3 \cdot 1(1 \cdot 5)\end{array}$ & $\begin{array}{l}106(29) \\
135(80) \\
146(59)\end{array}$ & $\begin{array}{l}6 \cdot 2(3.4) \\
6.1(3.2) \\
6.6(2.9)\end{array}$ \\
\hline
\end{tabular}

Values are mean (2SD) and units are $\mu \mathrm{g} / \mathrm{l}$ except for pyridinoline and deoxypyridinoline which are expressed as $\mathrm{nmol} / \mathrm{mmol}$ creatinine.

difference $(p>0 \cdot 2)$ in prevalence or severity of low $\mathrm{T}$ scores. Vertebral and hip $\mathrm{T}$ scores did not correlate significantly with body mass index or duration of disease $(r=0.22$ to -0.23 , $\mathrm{p}>0.05)$. However, patients diagnosed within two years $(\mathrm{n}=32)$ had significantly $(\mathrm{p}<0.04)$ higher vertebral $\mathrm{T}$ scores $(-0.47(1.62) v-1.23$ $(1 \cdot 60))$ than those with disease duration of over two years, but hip $\mathrm{T}$ scores did not differ significantly $(-2.04(1.33) v-1.99(1.30))$. There were no significant $(p>0 \cdot 1)$ differences in $T$ scores for vertebrae or hips between patients with Crohn's disease and those with ulcerative colitis or within the patient subgroups according to disease location (small intestinal + ileal $v$ ileocaecal + ileocolonic $v$ colonic Crohn's disease or ulcerative proctosigmoiditis $v$ extensive ulcerative colitis).

\section{Possible effect of corticosteroids}

The possible effect of steroids was assessed, firstly, by comparing the prevalence and severity of reduced bone mineral density in patients who were taking corticosteroids at the time of study and those who were not. There

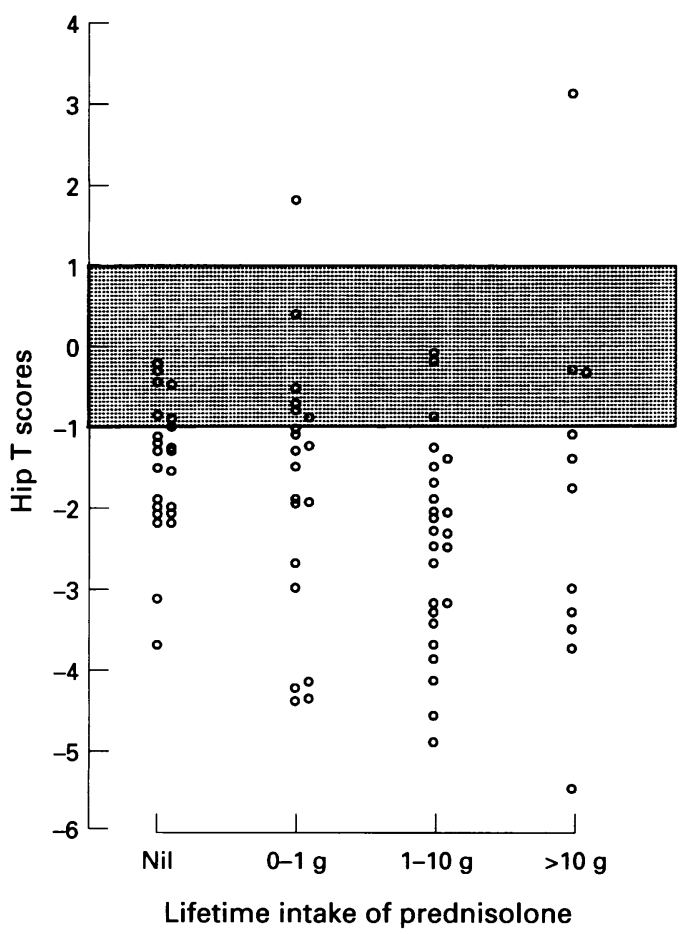

Figure 2: Hip T scores and cumulative lifetime intake of corticosteroids. Newly diagnosed patients and patients who had never received corticosteroids have similar frequency of reduced bone mineral density at those who have taken corticosteroids but a greater proportion of patients that had received corticosteroids had osteoporosis as defined by a $T$ score $<-2 \cdot 5^{11}$ was no significant difference $(p>0.5)$ between the vertebral or hip $\mathrm{T}$ scores between the two groups.

Secondly, vertebral and hip $\mathrm{T}$ scores did not correlate significantly $(r=-0.18$ and -0.11 respectively, $p>0.05$ ) with lifetime intake of corticosteroids.

Thirdly, we compared the prevalence and severity of low bone mineral densities in patients who had never received corticosteroids $(n=23)$ (including untreated, newly diagnosed patients) with those of patients who had received corticosteroids. Figure 2 shows that there was no significant difference (Wilcoxon) for mean hip $T$ scores between patients who had not received corticosteroids and those who had received a cumulative prednisolone intake $<1 \mathrm{~g}, 1-10 \mathrm{~g}$, and $>10 \mathrm{~g}$. However, of the patients with hip $\mathrm{T}$ scores $<-2 \cdot 5$, two of 23 $(10 \%)$, six of $20(30 \%), 11$ of $25(44 \%)$, and five of $11(45 \%)$ had a cumulative prednisolone intake of $0,<1 \mathrm{~g}, 1-10 \mathrm{~g}$, and $>10 \mathrm{~g}$ respectively.

When newly diagnosed patients were analysed separately, patients with ulcerative colitis (five out of six) had normal $\mathrm{T}$ scores for vertebrae and hips whereas six out of eight patients with Crohn's disease had T scores less than -1 .

\section{Calcium homeostasis}

Serum calcium $(2 \cdot 4$ (SD $0 \cdot 1) \mathrm{mmol} / \mathrm{h}$, normal $2 \cdot 2-2.6 \mathrm{mmol} / \mathrm{l})$, phosphate $(1 \cdot 2$ (SD) 0.2 $\mathrm{mmol} / \mathrm{l}$, normal $0.8-1.4 \mathrm{mmol} / \mathrm{l}$ ), and parathyroid hormone (30 (21) ng/l, normal $<90$ $\mathrm{ng} / \mathrm{l})$ concentrations were normal in all patients. The mean urinary calcium $(0.27$ (SD $0.24) \mathrm{mmol} / \mathrm{mmol}$ creatinine, normal 0.30 (SD $0.25) \mathrm{mmol} / \mathrm{mmol}$ creatinine) was slightly below the normal but did not differ significantly from controls.

\section{Osteoblast marker activities}

Alkaline phosphatase (74 (SD 22) IU/l, normal 30-120 IU/1) was within normal limits in all the patients and P1CP (129 (SD 58) $\mu \mathrm{g} / \mathrm{l})$ and osteocalcin $(6.2(\mathrm{SD} 3.0) \mu \mathrm{g} / \mathrm{l})$ concentrations $(n=52)$ did not differ significantly from controls (130 (SD 42) $\mu \mathrm{g} / 1$ and $8 \cdot 7$ (SD 4.4) $\mu \mathrm{g} / \mathrm{l}$ respectively).

There were no significant differences $(p>0.25)$ in P1CP or osteocalcin concentrations between patients with Crohn's disease and ulcerative colitis or patients $(n=19)$ receiving (10 mg prednisolone/day) or not receiving corticosteroids. The markers did not correlate significantly $(p>0.3)$ with cumulative prednisolone intake and there was no significant difference between smokers and nonsmokers.

\section{Osteoclast marker activities}

Figure 3 shows that pyridinoline (46.1 (SD 26.9) $\mathrm{nmol} / \mathrm{mmol}$ creatinine (normal 22 (SD 10) $\mathrm{nmol} / \mathrm{mmol} /$ creatinine)) and deoxypyridinoline (11.1 (SD 6.7) $\mathrm{nmol} / \mathrm{mmol}$ creatinine, normal $5 \cdot 2(\operatorname{SD~} 2 \cdot 8) \mathrm{nmol} / \mathrm{mmol}$ creatinine) 


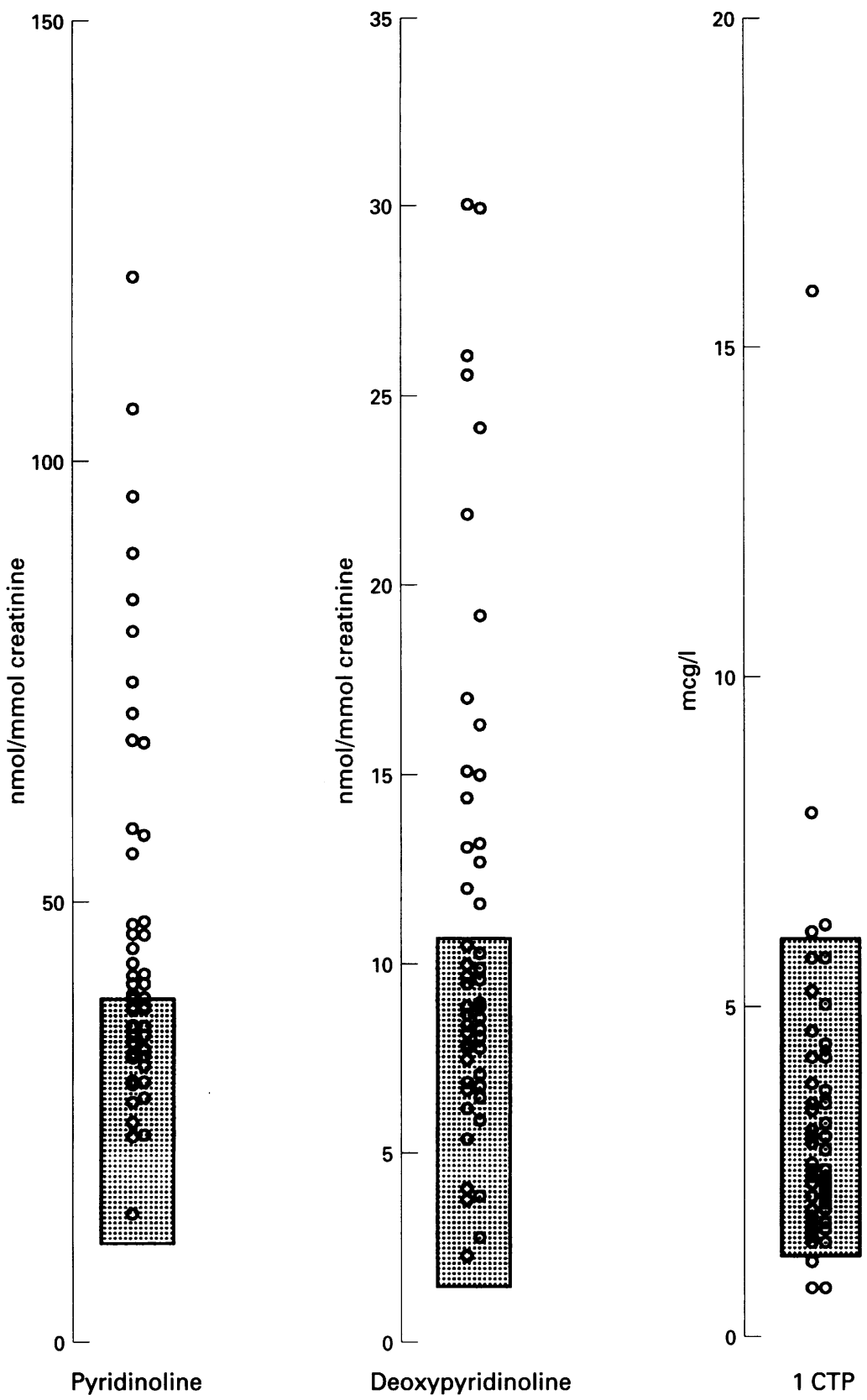

Figure 3: Bone resorption markers are significantly increased (apart from 1CTP) in patients with inflammatory bowel disease. The shaded area represents the normal range (2 SD).
Relation between bone mineral densities and biochemical markers of bone turnover Vertebral and hip bone density $\mathrm{T}$ scores did not correlate significantly with any of the osteoblast or osteoclast markers ( $r=$ between -0.22 and $0 \cdot 28 ; \mathrm{p}>0 \cdot 1$ ). Table I shows that there was no significant difference between bone resorption and formation markers from patients with $T$ scores within the reference range and those with osteopenia or osteoporosis, although there is a trend for patients with osteopenia to have higher and those with osteoporosis to have lower resorption marker values than those that are within the reference range. P1CP values, but not osteocalcin, tended to increase proportional to the degree of reduced bone mineral density, but this did not reach significance.

A similar trend was found in respect of vertebral bone mineral density but again this did not achieve significance.

\section{Discussion}

We have shown a high prevalence of reduced bone mineral density in patients with inflammatory bowel disease which is independent of site or type of disease (Crohn's disease or ulcerative colitis) and which is not simply due to corticosteroids. However, patients with very low $\mathrm{T}$ scores at the hip (<-2.5: osteoporosis) are more likely to have received relatively large doses of steroids. The mechanism of reduced bone density seemed to be due to increased bone resorption without a compensatory increase in bone formation, which differs from that found in other metabolic bone diseases.

The results need to be examined in the context of previous studies, but such comparisons are complicated by variability in patient selection, the sites studied (radial, vertebral, or hip bone densities), the methods of measurement, and expression of results which differ in their sensitivity and specificity. Nevertheless, it had been suggested that patients with inflammatory bowel disease at risk for osteoporosis were those with longstanding small bowel disease, patients that had undergone intestinal resection, patients with amenorrhoea (hypooestrogenism), or those on high dose corticosteroid treatment. ${ }^{12} 16$ Postmenopausal women, who are independently at risk from osteoporosis, ${ }^{3}{ }^{17}$ were often included in these studies, further complicating the issue. We aimed for a rather more homogeneous group of patients who did not have the known risk factors for reduced bone mineral density apart from some corticosteroid treatment and tobacco use.

In keeping with previous studies using DXA the prevalence of reduced bone mineral density did not differ significantly between patients with longstanding Crohn's disease and ulcerative colitis. ${ }^{81618}$ There was, however, a noticeable difference in the significantly higher prevalence of reduced bone mineral density in the hips (cortical bone) than in vertebrae (trabecular bone). This is a different pattern from that of postmenopausal, ${ }^{7}$ steroid and tobacco induced bone disease, ${ }^{14-21}$ which affect trabecular bone to a greater extent than cortical bone. clast marker activities in patients with diagnosed (within two years) or longstand (more than two years) disease. The markers did not correlate significantly $(p>0.3)$ with cumulative or concurrent prednisolone intake and there was no significant difference between smokers and non-smokers. 
Pigot et $a l^{16}$ and Ghosh et al ${ }^{18}$ reported comparable severity of reduced bone mineral density in vertebra and hip and vertebra and forearm. However, any preferential effect on hips in these studies, and others, may have been obscured by the heterogeneity of patients many of whom were at risk for reduced bone mineral densitites for other reasons. ${ }^{2} 381518$ The selective increase in two of three osteoclast marker activities further suggests that the mechanism of reduced bone density in patients with inflammatory bowel disease differs from that of postmenopausal women (in whom P1CP and osteocalcin are significantly increased $)^{22}$ or that associated with tobacco use (no changes in osteocalcin, alkaline phosphatase, hydroxyproline, or pyridinoline).$^{21}$ The failure to show a significant effect of corticosteroids or tobacco smoking on bone markers in our study may be due to the few patients studied or that any such effect is overshadowed by changes associated with inflammatory bowel disease.

We found that newly diagnosed patients with Crohn's disease and patients that had never received corticosteroids have reduced bone mineral density, in keeping with the findings of Ghosh $e a^{18}$ who studied 30 newly diagnosed patients and additionally found no significant contribution of corticosteroids to the reduced bone loss on follow up. These findings raise the possibility that demineralisation occurs in response to the intestinal inflammation itself. One possibility is that spill over of cytokines from the inflamed intestine into blood, ${ }^{24-28}$ such as interleukin 1 or tumour necrosis factor (stimulate osteoblasts to release an osteoclast activating factor), interleukin 6 , macrophage, or granulocyte stimulating factors (which increase the number of osteoclast progenitor cells) - lead to the low bone mineral densities. ${ }^{28}{ }^{29}$ If correct, this would explain the lack of correlation between the severity of reduced bone mineral density and the bone formation and resorption markers as the first is the cumulative effect over years whereas the bone markers would be subject to short term control. Accordingly the average of three years from the onset of symptoms to diagnosis ${ }^{30}$ of Crohn's disease would explain the higher prevalence of low bone mineral densities than that found in patients with ulcerative colitis in whom the diagnosis is made earlier. However, other pathogenic factors such as reduced physical activity and altered body composition may also be important and are not ruled out by our study.

Collectively we have shown a high prevalence of low mineral densities in patients with inflammatory bowel disease which is unrelated to surgery, type and site of disease, or treatment with corticosteroids. The greater frequency of low mineral density in hips than vertebrae and the pattern of osteoblast and osteoclast marker activities suggest a different mechanism of bone disease from other known causes of osteoporosis.
1 Genant HK, Mall JC, Wagonfield JB, et al. Skeletal demineralisation and growth retardation in inflammatory bowel disease. Invest Radiol 1976; 11: 541-9.

2 Compston JE, Judd D, Crawley EO, et al. Osteoporosis in patients with inflammatory bowel disease. Gut 1987; 28: $410-5$

3 Genant HK, Cann CE, Ettinger B, Gordon GS Quantitative computed tomography of vertebral spongiosa. A sensitive method for detecting early bone loss after oophorectomy. Ann Int Med 1982; 97: 699-705.

4 Fromm $\mathrm{H}$. Consequences of reduced absorption: stone and bone disease. In: Scholmeric J, Kruis W, Goebell $\mathrm{H}$, Hohenberger W, Gross V, eds. Inflammatory bowel disease. Pathophysiology as basis of treatment. Falk Symposium 67. Dordrecht: Kluwer Academic Publishers, 1993: 231-9.

5 Leichtmann G, Bengoa JM, Bolt MJG, Sitrin MD Intestinal absorption of calciferol and 25-hydroxycholecalciferol in patients with both Crohn's disease and intestinal resection. Am $\mathcal{F}$ Clin Nutr 1991; 54: 548-52.

6 Harries AD, Brown R, Heatley RV, Williams LA, Woodhead JS, Rhodes J. Vitamin D status in Crohn's disease: association with nutrition and disease activity. Gut 1985; 26: 1197-203.

7 Clements D, Compston JE, Evans WD, Rhodes J. Hormone replacement therapy prevents bone loss in patients with inflammatory bowel disease. Gut 1993; 34: 1543-6.

8 Vogelsang H, Ferenci P, Woloszenzk W, et al. Bone disease in vitamin D-deficient patients with Crohn's disease. Dig Dis Sci 1989; 34: 1094-9.

9 Best WR, Becktel JM, Singleton JW, Kern R. Development of a Crohn's disease activity index. Gastroenterology 1976; 70: 439-44.

10 Truelove SC, Witts LJ. Cortisone in ulcerative colitis: final report on a therapeutic trial. BMF 1955; 2: 1041-4.

11 Suleiman S. A screening questionnaire for post-menopausal osteopenia. [PhD thesis]. London: University of London, 1991.

12 Kanis JA, Melton J, Christiansen C, Johnston CC, Khaltev N. The diagnosis of osteoporosis. $\mathcal{f}$ Bone Miner Res 1994; 9: $1137-41$.

13 Melkko J, Seija N, Risteli J. Radioimmunoassay of the carboxy-terminal propeptide of human type I procollagen. Clin Chem 1990; 39: 1328-32.

14 Monaghan D, Power M, Fottrell P. Sandwich enzyme immunoassay of osteocalcin in serum with an antibody against human osteocalcin. Clin Chem 1993; 36: 942-7.

15 Risteli J, Elomaa I, Niemi S, Novamo A, Risteli L. Radioimmunoassay for the pyridinoline cross-linked carboxyterminal teleopeptide of type I collagen: a new serum marker

16 Pigot F, Roux C, Chaussade S, et al. Low bone density in patients with inflammatory bowel disease. Dig Dis $S c i$ 1992; 37: 1396-403.

17 Prince RL, Smith M, Dick IM, et al. Prevention of postmenopausal osteoporosis. N Engl f Med 1991; 325: 1189-95.

18 Ghosh S, Cowen S, Hannan WJ, Ferguson A. Low bone mineral density in Crohn's disease, but not in ulcerative mineral density in Crohn's disease, but not in ulcerative

19 Lukert BP, Raisz LG. Glucocorticoid-induced osteoporosis: pathogenesis and management. Ann Intern Med 1990; pathogenesis

20 Slemenda CW, Hui SL, Longcope C, Johnston CC. Cigarette smoking, obesity, and bone mass. $\mathcal{F}$ Bone Miner Res 1989; 4: 737-41.

21 Hopper JL, Seeman E. The bone density of female twins discordant for tobacco use. $N$ Engl $f$ Med 1994; 330 : 387-92.

22 Hassanger C, Fabbri-Mabelli G, Christiansen C. The effect of the menopause and hormone replacement therapy on serum carboxyterminal propeptide of type 1 collagen. Osteoporosis Int 1993; 3: 50-2.

23 Johansen JS, Riis BJ, Delmas PD, Christiansen C. Plasma BGP: an indicator of spontaneous bone loss and of the effect of oestrogen treatment in postmenopausal women. effect of oestrogen treatment in p

24 Fiocchi C. Production of inflammatory cytokines in the intestinal lamina propria. Immun Res 1991; 10: 239-46.

25 Mueller C, Knoflach P, Zielenski CC. T-cell activation in Crohn's disease. Increased levels of soluble interleukin-2 receptor in serum and in supernatants of stimulated peripheral blood mononuclear cells. Gastroenterology 1990; 98: 639-46.

26 Gross V, Andus T, Caesar I, Roth M, Scholmerich J. Evidence for continuous stimulation of interleukin-6 production in Crohn's disease. Gastroenterology 1992; production

27 Duane P, Teahon K, Crabtree JE, Levi AJ, Heatley RV, Bjarnason I. The relationship between nutritional status and serum interleukin 2 receptor concentrations in patients with Crohn's disease treated with elemental diet. Clin Nutr 1991; 10: 222-7.

28 Meghji S. Bone remodelling. Br Dental f 1992; 172: 235-42.

29 Thomson BM, Saklatvala J, Chambers TJ. Osteoblasts mediate interleukin-1 on bone turnover in normal mice. F Exp Med 1986; 164: 104-12.

30 Mekhjian HS, Swite DM, Melnyk CS, Rankin GB Brooks RK. Clinical features and natural history of Crohn's disease. Gastroenterology 1979; 77: 898-906. 